\title{
Algunas consideraciones acerca del paralelo ético-jurídico en Religión de Kant
}

\author{
Noelia Eva Quiroga \\ Universidad de Buenos Aires \\ noeliaeva.quiroga@gmail.com \\ https://orcid.org/0000-0002-2934-6510
}

Resumen: En este trabajo me propongo contribuir a comprender el paralelo éticojurídico trazado en Religión dentro de los límites de la mera razón. Analizaré las semejanzas, las diferencias y la analogía entre el estado de naturaleza, el exeundum y la comunidad éticos, por un lado, y el estado de naturaleza, el exeundum y la comunidad jurídico-políticos, por el otro. Argumentaré que el progreso moral, entendido como superación del mal radical, requiere un complemento entre el dominio ético y el jurídico-político, dado que cada dominio aporta un abordaje y una solución comunitaria diferente dentro de la misma esfera pública.

Palabras clave: Kant; estado de naturaleza; comunidad; deber; progreso

\begin{abstract}
Some Reflections on the Ethical-legal Parallel in Kant's Religion". The aim of this paper is to contribute to understanding the ethical-legal parallel drawn in Religion within the Boundaries of Mere Reason. I will analyze the similarities, differences and the analogy among the ethical state of nature, the exeundum and the community, on the one side, and the juridical state of nature, the exeundum and the community, on the other. I will argue that moral progress, understood as overcoming radical evil, requires a complement between the ethical and legalpolitical spheres, given that each area provides a different approach and a different community solution within the same public sphere.
\end{abstract}

Keywords: Kant; state of nature; community; duty; progress 


\section{Introducción}

En la Tercera Parte de Religión dentro de los limites de la Mera Razón ${ }^{1}$, Kant presenta su originalidad en relación con la tradición del contrato social al trazar un paralelo entre el estado de naturaleza, el exeundum y la comunidad éticos, por un lado, y el estado de naturaleza, el exeundum y la comunidad jurídico-políticos, por el otro. A partir de este paralelo Kant introduce la llamada "analogía política", la cual consiste en que, así como debemos abandonar el estado de naturaleza jurídico para conformar un estado civil político, de la misma manera debemos abandonar el estado de naturaleza ético para conformar una comunidad ética ( $R G V$, VI: 97, [122]) $)^{2}$. Sin embargo, como ha señalado Kyla Ebel-Duggan, las observaciones sobre el paralelo ético-jurídico que Kant traza (respecto a la salida del estado de naturaleza y la entrada a una comunidad) "son ricas en sugerencias, pero decepcionantemente vagas"3. Por ello, en este trabajo me propongo contribuir a comprender en qué consiste el paralelo éticopolítico ${ }^{4}$, trazado en Religión, a partir del análisis de sus partes.

En la literatura podemos encontrar diversas lecturas respecto a cuál es o debe ser la relación entre el dominio ético y el jurídico-político en Religión. Por un lado, encontramos quienes consideran que existe una relación entre el dominio ético y el jurídico-político para alcanzar el progreso partiendo desde el mal, en tanto que la comunidad ética es la que permitiría superar el mal radical que se manifiestan en contextos socio-politicos ${ }^{5}$. Por otro lado, frente a dichas

1 En adelante me referiré a esta obra de forma abreviada como Religión.

2 Siguiendo el uso establecido, en las referencias a las obras de Kant se citan primero por medio de la sigla de la obra correspondiente seguidos por el volumen y la página de Kants gesammelte Schriften (Academia Alemana de Ciencias, Berlin), seguidos, entre corchetes, por la página en la traducción castellana consignada en la bibliografia al final del artículo.

3 Ebel-Duggan, K., "Moral Community: Escaping the Ethical State of Nature", en: Philosophers' Imprint, v. IX, 8 (2009), p. 1.

3164 En el presente trabajo desarrollo en profundidad los rasgos y la fundamentación de la relación entre la comunidad política y la comunidad ética que estudié de forma introductoria en: Quiroga, N., "El origen, objetivo y función de la comunidad ética en La religión dentro de los límites de la mera razón de Kant”, Anales del Seminario de Historia de la Filosofia, v. XXXVII, 3 (2020), pp. 445-447.

5 En esta mano tenemos las distintas propuestas. Philip Rossi, para quien el logro del bien supremo depende del cumplimiento de dos conjuntos de condiciones interdependientes que proporcionan el contexto para la conducta moral humana y las prácticas sociales. El primer grupo de condiciones provienen de los dinamismos internos, de acuerdo a los cuales las personas gobiernan de forma autónoma su propia conducta individual. Y el segundo grupo de condiciones 


\section{interpretaciones, encontramos quienes consideran que el progreso consiste en la superación del vacío legal, excluyendo un punto de partida en el mal' .}

provienen del orden externo, de acuerdo a los cuales los seres humanos se regulan mutuamente la conducta a través de las instituciones y prácticas sociales, fundamentalmente mediante el establecimiento de un orden público en el que la autoridad política legítima recae sobre el Estado (Cf. Rossi, P., The social Authority of Reason: Kant's Critique, Radical Evil, and the Destiny of Humankind, Albany: State University of New York Press, 2005, pp. 77-81). James DiCenso considera que la interrelación kantiana entre el dominio ético y el jurídico-político es abordada, por un lado, mediante el cultivo de instituciones éticas, es decir, recursos públicos no coactivos que se desarrollan en medio de las sociedades politicas y que contribuyen a que las instituciones políticas sean más justas, como también a articular y difundir los principios de la ley moral. Por otro lado, la sociedad civil ética requiere el apoyo de las condiciones de derecho público que promueven la libertad de expresión racional y la difusión de ideas morales racionales $(C f$. DiCenso, J., Kant's Religion within the Boundaries of Mere Reason: A Commentary, Cambridge: Cambridge University Press, 2012, pp. 134-135; DiCenso, J., "Kant on ethical institutions", en: The Southern Journal of Philosophy, v. LVII, 1 (2019), pp. 30-33 y 44). Pablo Muchnik sostiene que las preocupaciones éticas y las jurídico-políticas se complementan en el sentido de que la garantía de la paz no puede ser meramente jurídico-política. Pues, aunque la pacificación se logre a través del poder del Estado, ese logro es incierto, porque permite que una "nación de demonios inteligentes" permanezca tan malvada como lo fue en el estado de naturaleza. Entonces, para que la esfera jurídico-politica tenga efectividad para pacificar, se quiere un complemento, a saber, que la paz sea adoptada como un fin en sí mismo por cada uno de los demonios inteligentes. Eso solo es posible mediante el ejercicio coordinado del uso de la libertad interna por parte de agentes individuales. Esta coordinación tiene por resultado que las voluntades particulares se unan en búsqueda del fin compartido de la paz. La unidad colectiva para alcanzar la paz duradera es posible mediante la comunidad ética ( $C f$. Muchnik, P., "Kant's religious constructivism", en: Michalson, G. (ed.), Kant's Religion within the Boundaries of Mere Reason. A critical Guide, Cambridge: Cambridge University Press, 2014, pp. 201-205). En acuerdo con Muchnik, Nicholas Tampio sostiene que una "nación de demonios" es insuficiente para remediar la corrupción moral entre agentes prácticos auto-reflexivos. Para superar la corrupción de la disposición moral por la que los seres humanos se hacen malvados, se requiere colaborar en una asociación bajo leyes de virtud, es decir, en una comunidad ética. La relación entre el dominio ético y el jurídico-político radica en que un agente moral requiere seguir la ley moral para superar el mal radical, pero a la vez, no puede obviarse las dimensiones sociales, es decir, la dimensión política en las cuales se realiza la acción moral (Cf. Tampio, N., "Pluralism in the Ethical community", en: Gordon M. (ed.), Kant's Religion within the Boundaries of Mere Reason: A critical Guide, Cambridge: Cambridge University Press, 2010, pp. 181-182). Finalmente, encontramos a Paul Guyer para quien la comunidad política no debe ser considerada solo como un peldaño desde donde avanzar hacia una comunidad ética y ser dejada atrás una vez que se ha logrado la comunidad ética. Pues el grado más elevado de virtud que podemos alcanzar los seres humanos es la creación de condiciones politicas que al menos impongan el cumplimiento externo de las exigencias de la moralidad. Así, el bien más elevado requeriría el bien político supremo, el cual no puede ser producido sin la motivación virtuosa de al menos algunos seres humanos, a saber, los "políticos morales" (Cf. Guyer, P., "Kantian Communities: The Realm of Ends, the Ethical Community, and the Highest Good", en: Payne, C. y L. Thorpe (eds.), Kant and the Concept of Community, Nueva York: University of Rochester Press, 2011, pp. 116-118).

6 En esta dirección se encuentran: Laura Papish, para quien, a diferencia de Rossi, la analogía entre el estado de naturaleza ético y el jurídico, en el nivel de los individuos como de los Estados, es utilizada para mostrar que ni la conformación de una comunidad ética ni la de una comunidad política son correctivas de la llamada "presunción de maldad". El mal no está caracterizado por agresión, extralimitación malintencionada, codicia o avaricia, sino que para Papish el mal, siguiendo a Pinheiro Walla, radica en que el otro individuo o Estado se niegue a formar una 
Para posicionarme con respecto al progreso moral, en acuerdo con el primer grupo mencionado, en este trabajo argumentaré a favor de que existe una analogía entre los constructos éticos y jurídico-políticos. Pues Kant establece una analogía con respecto a la relación estructural entre el estado de naturaleza ético y la comunidad ética, por un lado, y el estado de naturaleza jurídico y la comunidad política, por el otro. Ambos estados de naturaleza -en los cuales no hay ley común, sino que los individuos se dan a sí mismos las leyes- deben ser abandonados para alcanzar una unidad en una sociedad civil bajo leyes comunes, una ética y la otra jurídica-política.

Asimismo, argumentaré que la falta de ley común, es decir, pública, es lo que profundiza el mal que caracteriza los estados de naturaleza, en los cuales las personas se guían por las máximas del amor propio que los lleva a la competencia y al intento de dominación de unos sobre los otros. Considero que la falta de ley común no anula el punto de partida del mal, sino que lo fundamenta y, a su vez, contribuye a entender la idea kantiana de progreso dada por la conformación de la comunidad ética.

Mi propósito es mostrar que el progreso moral, entendido como superación del mal radical existente en los estados de naturaleza, requiere un complemento entre el dominio ético y el político, pues cada dominio aporta un abordaje y una solución diferente dentro de la misma esfera pública. Si bien la comunidad ética abarca y supera a la comunidad política, en tanto que la primera está conformada con la base de la segunda, sin la cual no podría existir, sin embargo, ello no implica que en la tarea de lograr un progreso moral ambas comunidades no estén interrelacionadas, sino todo lo contrario. Pues la

sociedad civil. Lo que caracteriza los estados de naturaleza ético y jurídico, entre individuos o entre Estados, es la falta de leyes comunes y la salida del estado de naturaleza es una necesidad racional a priori (Cf. Papish, L., Kant on evil, Self-Deception, and Moral Reform, Nueva York: Oxford University Press, 2018, pp. 205, 214). Por su parte, Stephen Palmquist sostiene que la comunidad política puede ser una metáfora de lo ético, en el sentido de que la comunidad ética es un tipo de reino. La idea de que un reino ético tiene "realidad objetiva" no descansa en una ingenua (por ejemplo, utópica) esperanza de que prevalezca "la buena voluntad de los seres humanos", sino más bien en el simple hecho de que la razón nos impone tal exigencia, es decir, el deber de erigirla. Sin embargo, Palmquist sostiene que ello no debe confundirse con la consideración de que la reforma religiosa que se llevaría a cabo con la conformación de la comunidad ética sea un paso más en el progreso político, tal como sostienen por ejemplo Rossi y DiCenso. Asimismo, destaca que el paralelismo entre la construcción de las comunidades ética y politica tienen tres etapas. Primero, un estado de naturaleza sin ley común. Segundo, el desarrollo de las comunidades acordando leyes comunes. Por último, la unidad de todas las sociedades distintas conformando el derecho internacional, por un lado, y el todo ético absoluto, por el otro ( $C f$. Palmquist, S., Comprehensive Commentary on Kant's Religion within the Bounds of Bare Reason, Chichester: Wiley Blackwell, 2016, pp. 254-255, 259). 
comunidad política representa el estado de naturaleza ético, caracterizado por el mal radical, desde donde partimos para trabajar en el progreso moral ético de los seres humanos. Nuestras elecciones éticas se dan en un contexto social, en medio de una comunidad política. Con ambas comunidades se conforma el espacio público en el que interactuamos.

Para defender dichas tesis, en primer lugar, analizaré en qué consiste el estado de naturaleza jurídico y el estado de naturaleza ético, en donde se verá que ambos estados están caracterizados por la falta de leyes comunes y por el conflicto entre los seres humanos como su consecuencia. En segundo lugar, a partir de los estados de naturaleza descriptos, analizaré en qué consiste el exeundum ético y el jurídico, en donde se verá que ambos son deberes de la razón pura práctica, aunque de diferente tipo. En tercer lugar, analizaré la conformación de los estados civiles kantianos como soluciones comunitarias a la falta de ley común y al mal, cuya posibilidad está dada por dos principios de unidad diferentes, a saber, la voluntad unida de todos y Dios. Finalmente, a partir de este recorrido, daré una conclusión con respecto a la interrelación entre el dominio ético y jurídico-político.

\section{El estado de naturaleza ético y el juridico}

En la Tercera Parte de Religión, Kant recurre a constructos propios de las teorias del contrato social -a saber, al estado de naturaleza y al exeundum-, pero para mostrar por qué debemos conformar una comunidad ética, y ello lo hace comparando permanentemente los constructos éticos con los jurídicopolíticos. De allí surge el interés por comprender en qué sentido Kant utiliza el paralelismo ético-jurídico como una analogía ${ }^{7}$.

Como es sabido, la importancia de la caracterización del estado de naturaleza radica en que es la base para la justificación que se dará del exeundum, es decir, de aquello que lleva a abandonar el estado de naturaleza.

Al igual que en su relato sobre el estado de naturaleza jurídico, en su relato sobre el estado de naturaleza ético Kant resulta ambiguo con respecto a si la característica fundamental de dicho estado es la "presunción de maldad"

\footnotetext{
7 Aquí no me detendré en el análisis exhaustivo de los elementos jurídicos, dado que ello excedería los límites y propósitos de este trabajo, sino que solo me limitaré a reponer sus características elementales con el fin de compararlos con los elementos éticos. Y dado que los elementos jurídicos son introducidos de forma muy breve en Religión, complementaré su explicación con algunas aclaraciones que Kant brinda principalmente en el texto posterior de Metafisica de las Costumbres, como así también algunas aclaraciones relevantes que se encuentran en los textos de Teoría y Praxis y La Paz Perpetua, los cuales fueron escritos en el mismo período que Religión.
} 
o si es la "falta de ley común pública". Esto ha dado lugar a distintas interpretaciones en la literatura.

Del lado jurídico, la posición referente de la "presunción de maldad" es la sostenida por Sharon Byrd y Joachim Hruschka, que caracteriza al estado de naturaleza jurídico como un estado de conflictividad e inseguridad, pues se basan en el §42 de la Doctrina del Derecho que dice que "nadie está obligado a abstenerse de invadir lo que otro posee si el otro no le da la misma seguridad de que observará la misma restricción hacia él” (RL, VI: 307, [137], traducción enmendada), y que uno "está autorizado a coaccionar a quien, ya por naturaleza, le amenaza con ello (con la violencia)" (RL, VI: 307, [138]). De ahí sostienen que son las razones prudenciales, frente a la disposición humana a la agresión y al dominio sobre el prójimo, lo que lleva a tomar medidas preventivas para defender nuestros derechos. Es la presunción de maldad (a saber, que se presume que todos son malvados hasta que se proporciona la seguridad para lo contrario) la que nos permite obligar a los demás a abandonar el estado de naturaleza y pasar a un estado de derecho ${ }^{8}$. Los autores sostienen que "el uso de la coacción para hacer cumplir un derecho está permitido en la medida en que se requiere para defender el derecho" 9 . En el estado de naturaleza ese derecho es provisional y solo quedaría garantizado si ingresamos a un estado de derecho, pues al hacerlo garantizamos mutuamente la "seguridad" de que no interferiremos con las posesiones de nadie ${ }^{10}$.

Contra dicha interpretación encontramos la de Alice Pinheiro Walla, para quien no es la conflictividad ni la inseguridad lo que caracteriza el estado de naturaleza, sino que es la falta de un derecho perentorio. No puede pensarse que la prudencia es lo que nos lleva a abandonar el estado de naturaleza jurídico porque ello no explica por qué sería legítima la coacción unilateral ${ }^{11}$, si tenemos en cuenta la definición de coacción de §̧D de la Doctrina del Derecho que dice que la coacción unilateral viola formalmente el derecho por ser un obstáculo a la libertad ${ }^{12}$. Para la autora lo que caracteriza el estado pre-civil es ser un

3208 Byrd, S. y J. Hruschka, Kant's Doctrine of Right. A Commentary, Cambridge: Cambridge University Press, 2010, p. 190.

9 Ibid., p. 189.

${ }^{10}$ Ibid., p. 193.

${ }^{11}$ Pinheiro Walla, A., "Human Nature and the Right to CoerceKant's Doctrine of Right", en: Archiv für Geschichte der Philosophie, v. XCVI, 1 (2014), p. 132.

${ }_{12}$ Pinheiro Walla, "Human Nature and the Right to Coerce in Kant's Doctrine of Right", 2014, p. 138. Por otro lado, en esta misma dirección podemos ubicar a Macarena Marey, quien sostiene que la salida del estado de naturaleza se trata de un deber categórico a priori de nuestra razón pura práctica y no de una motivación subjetiva y de un acto que pueda dejarse al consentimiento 
estado normativo inconcluso de los derechos ${ }^{13}$. Y respecto al $\S 42$, sostiene que tiene la función de ser "una ilustración de las deficiencias normativas del estado de naturaleza, a las que una condición de justicia pública es la solución"14.

Del lado ético, autores como Anderson-Gold, Wood, Rossi, DiCenso ${ }^{15}$, podríamos decir en paralelo a la lectura de Byrd y Hruschka sobre el estado de naturaleza jurídico marcado por la inseguridad, sostienen que el estado de naturaleza ético es un estado de permanentes ataques del principio malo sobre el principio bueno ( $R G V$, VI: 97, [121]) y es cuando estamos en contacto con los otros que nos hacemos más vulnerables éticamente, es decir, estamos más proclives a corrompernos éticamente (RGV: VI, 93 [117-118]). Así como debemos salir del estado de naturaleza jurídico para asegurar la propiedad y la libertad externa, de la misma manera debemos abandonar el estado de naturaleza ético y conformar una comunidad ética para reordenar las relaciones sociales y coordinar un fin común para nuestras libertades internas.

Frente a esta interpretación podemos hallar la de Laura Papish, quien considera, siguiendo las críticas de Pinheiro Walla a la interpretación del estado de naturaleza jurídico caracterizado por la inseguridad y la conflictividad, que el estado de naturaleza ético no está caracterizado por el mal entendido como agresión, extralimitación malintencionada, codicia o avaricia, sino que el mal radica en que el otro individuo se niegue a formar una sociedad civil. Lo que caracteriza el estado de naturaleza ético es la falta de ley común y la salida de dicho estado es una necesidad racional a priori ${ }^{16}$.

Ahora bien, hay que notar algo fundamental sobre esta discusión en Religión, a saber, que nadie niega que el estado de naturaleza consista en que cada individuo interpreta y ejecuta la ley a su manera. Lo cierto es que, en la Tercera Parte de Religión, Kant define a los estados de naturaleza ético

de las personas, como sería la búsqueda de la seguridad. La voluntad unilateral no puede imponer obligaciones a los demás, solo la voluntad omnilateral puede reclamar legítimamente la universalidad y la reciprocidad de las obligaciones juridicas (RL, §44, VI: 312, [141]) (cf. Marey, M., "The Originality of Kant's Social Contract Theory", en: Krasnoff, L. y otros (eds.), Kant's Doctrine of Right in the Twenty-first Century, Cardiff: University of Wales Press, 2018, pp. 9, 18-19).

${ }^{13}$ Pinheiro Walla, "Human Nature and the Right to Coerce in Kant's Doctrine of Right", p. 138.

14 Ibid., p. 135.

15 Cf. Anderson-Gold, S., "God and community: An Inquiry into the Religious implications of the Highest Good”, en: Rossi, P. y M. Wreen (eds.), Kant's Philosophy of Religion Reconsidered, Bloomington/Indianapolis: Indiana University Press, 1991, pp. 124-125; Wood, A., Kant's Ethical thought, Cambridge: Cambridge University Press, 1999, p. 314; Rossi, P., The social Authority of Reason: Kant's Critique, Radical Evil, and the Destiny of Humankind, p. 77; DiCenso, J., Kant's Religion within the Boundaries of Mere Reason: A Commentary, pp. 132-133.

16 Papish, L., Kant on evil, Self-Deception, and Moral Reform, p. 214. 
y jurídico como estados en los cuales los seres humanos se hallan sin ley común. En ambos estados "cada individuo se da a sí mismo la ley" porque "no hay ninguna ley externa, a la cual se reconozca sometido junto con todos los demás" (RGV, VI: 95, [120], traducción enmendada). La consecuencia de esta falta de ley común, en ambos estados de naturaleza, es que "cada individuo es su propio juez y no hay ninguna autoridad pública poseedora de poder, que según leyes determine con fuerza de derecho lo que en los casos que se presentan es deber de cada uno y lleve ese deber a general ejercicio" (RGV, VI: 95, [120], traducción enmendada).

Sin embargo, ello no está desconectado del mal radical y de sus manifestaciones en los contextos sociales, como así lo hace ver Papish, para quien la caracterización del estado de naturaleza no tiene nada que ver con el mal ${ }^{17}$. En cambio, sostengo que precisamente la falta de ley pública es lo que lleva a que cada persona en estado de naturaleza guíe sus acciones por el amor propio y que este sea la piedra de toque para la búsqueda del dominio sobre los demás y para el conflicto social traducido en rivalidad, envidias, codicia y guerras.

Esta relación entre la falta de ley pública y la conflictividad social puede verse en una nota al pie de Religión que Kant utiliza para aclarar que el estado de naturaleza que Hobbes ha caracterizado como un estado de guerra de todo hombre contra todo hombre (status hominum naturalis est bellum ómnium in omnes) no es tanto un estado de efectivas hostilidades, sino más bien un estado en el que la guerra está siempre latente porque es un estado de "lesión continua de los derechos de todos" (RGV, VI: 97n, [122]). Pues al no haber leyes exteriores comunes, eso provoca hostilidades entre los seres humanos, dado que cada uno es juez de sí mismo y con ello no se puede dar seguridad a los otros.

Así como el estado de naturaleza jurídico, sin leyes coactivas comunes, "es un estado de injusticia y guerra de todos contra todos" (RGV, VI: 97, [122]), así el estado de naturaleza ético, sin leyes públicas de virtud, "es un público hacerse la guerra mutuamente a los principios de virtud y un estado de interna amoralidad" (RGV, VI: 97, [122]). La falta de un principio ético que los una deja latente el acecho del mal, el cual hace que los seres humanos, como si fuesen instrumentos del mal, se centren en las disputas sobre los principios de virtud y se alejen del fin comunitario del bien supremo y, así, se pongan unos a otros en peligro de caer nuevamente bajo el dominio del mal (RGV, VI: 97, [121-122]).

${ }^{17}$ Ibid., pp. 214-215, 218. 
En el estado de naturaleza ético el mal siempre está acechando, incluso para quienes ya han hecho un cambio del corazón, es decir, que han comenzado a tomar a la ley moral como incentivo supremo al cual se subordinan todos los demás incentivos de las inclinaciones (RGV, VI: 47-48, [69-70]). Esto se debe a que el esfuerzo individual no puede garantizar el progreso moral si los demás no se comprometen también con dicho progreso. Sin este compromiso común, que solo puede estar garantizado por una unidad bajo leyes de virtud públicas, no hay garantía de que los seres humanos no se corrompan mutuamente. Un estado en el que no existen leyes públicas de virtud es un estado que da lugar a la corrupción de nuestra disposición para la humanidad. Esta disposición, que es originalmente buena, puede ser corrompida en cuando estamos en $\operatorname{sociedad}^{18}$ (RGV, VI: 27, [44]). Esto significa que en la comparación con los otros buscamos la propia valía y la dominación sobre los demás, actuamos siguiendo las máximas del amor propio y no las de la ley moral. La comparación con los otros conduce a los seres humanos a distintas formas de hostilidades ${ }^{19}$ que Kant llama vicios de la cultura, tales como la envidia, el ansia de dominio y la codicia ( $R G V$, VI: 27, [44]). Para Kant el conflicto ético es un conflicto que se activa en cuanto estamos en contacto con los otros, "basta que estén ahí, que lo rodeen, y que sean seres humanos, para que mutuamente se corrompan en su disposición moral y se hagan malos unos a otros" (RGV, VI: 94, [118]).

\section{El exeundum ético y el jurídico}

Como hemos visto hasta aquí, estructuralmente el estado de naturaleza ético se asimila al estado de naturaleza jurídico, pues ambos son estados caracterizados por la falta de ley común y por el conflicto social. Ahora bien, si nos preguntamos por qué los individuos tienen que abandonar el estado de naturaleza encontramos que nuevamente hay una semejanza estructural en el exeundum ético y el jurídico, dado que ambos responden a un deber de la razón

\footnotetext{
18 De ahí que muchos intérpretes han considerado que el mal como producto social es el resultado de la corrupción de nuestra disposición para la humanidad (Menschheit). Cf. Anderson-Gold, S., "God and community: An Inquiry into the Religious implications of the Highest Good", p. 124; Wood, A., Kant's Ethical thought, pp. 287-289; DiCenso, J., Kant's Religion within the Boundaries of Mere Reason: A Commentary, pp. 47-48 y 132.

19 Esta consideración de las hostilidades como productos de la sociabilidad es lo que llevado a algunos intérpretes a considerar a la propensión al mal como la "insociable sociabilidad" en Religión (Véase: Rossi, P., The social Authority of Reason: Kant's Critique, Radical Evil, and the Destiny of Humankind, pp. 78-79, 88; Wood, A., Kant's Ethical thought, pp. 287-289; Muchnik, P., "Kant's religious constructivism", p. 211; DiCenso, J., Kant's Religion within the Boundaries of Mere Reason: A Commentary, p. 35).
} 
pura práctica. Sin embargo, es aquí el momento en el que encontramos, a su vez, las diferencias fundamentales entre ambos constructos. Como veremos a continuación, las diferencias radican en el tipo de deberes y en el tipo de legislaciones correspondientes.

En Religión Kant dice que, así como debemos salir del estado de naturaleza jurídico para entrar en un estado civil político, así también debemos salir del estado de naturaleza ético tan pronto como sea posible (RGV, VI: 97, [122]).

Abandonar el estado de naturaleza (exeundum esse e statu naturali) es una consecuencia de cómo hemos caracterizado dicho estado ( $R G V$, VI: 97n, [122]). Solo si salimos del estado de naturaleza y entramos en un estado civil puede haber propiamente derecho y, con ello, seguridad (RGV, VI: $97 \mathrm{n}$, [122]). El exeundum no es una elección subjetiva del ser humano, sino que es un deber ${ }^{20}$ de la razón pura práctica. En Metafisica de las Costumbres Kant establece el postulado del derecho público en los siguientes términos: "en una situación de coexistencia inevitable con todos los demás, debes salir de ese estado [de naturaleza] y pasar a un estado jurídico-civil, es decir, a un estado de una justicia distributiva" ( $R L$, VI: 307, [137], traducción enmendada). Esto es, dada la inevitable coexistencia de las libertades externas, se debe entrar en un estado "en el que pueda asegurarse a cada uno lo suyo frente a los demás" ( $M S$, VI: 307, [47]). Y "cada uno está autorizado a ejercer aquella coacción que posibilite salir del estado de naturaleza e ingresar en el estado civil” (MS, VI: 264, [81]).

De forma paralela, el mal acecha en el estado de la naturaleza ético, que Kant caracteriza como "un público hacerse la guerra mutuamente a los principios de virtud" (RGV, VI: 97, [122]). Este mal se debe a que no hay una ley común pública de virtud y por ello las interacciones entre los seres humanos se basan en las máximas del amor propio. Dicho estado de naturaleza ético también debe abandonarse para pasar a conformar un estado civil ético donde todos los seres humanos guien sus acciones por leyes públicas éticas comunes.

Por un lado, sabemos por Metafisica de las Costumbres que salir del estado de naturaleza jurídico y entrar en un estado civil es un deber categórico a priori para "todos los seres humanos que pueden contraer (incluso involuntariamente) relaciones jurídicas entre sî" (MS, §41, VI: 306, [136], traducción enmendada). Se trata de un deber al que incluso uno puede ser obligado por la fuerza (MS, §44, VI: 312, [141]). Y salir del estado de naturaleza jurídico signi-

\footnotetext{
${ }^{20}$ Respecto al deber de conformar un estado civil Kant dice: "La constitución civil, aunque su realidad sea subjetivamente contingente, es no obstante necesaria objetivamente, es decir, como deber" (MS, VI: 264, [80]).
} 
fica unirse junto con todos los demás con los que no se puede evitar entrar en interacción y pasar a "someterse a una coacción externa legal y pública" ( $M S$, $\S 44$, VI: 312; [141], traducción enmendada). Dicha coacción legítima solo es posible mediante la legislación de "la voluntad concordante y unida de todos, en la medida en que deciden lo mismo cada uno sobre todos y todos sobre cada uno” (MS, §46, VI: 313-314, [143]). Solo así se generan obligaciones jurídicas reciprocas y legítimas. La voluntad unida de todos es el principio de unidad que hace posible la unidad de los seres humanos bajo leyes jurídicas.

Por otro lado, al igual que desde el punto de vista jurídico, en Religión Kant da una justificación normativa del exeundum ético. Tenemos la obligación ${ }^{21}$, en cuanto esté en nuestro alcance, de emplear nuestras fuerzas para salir del estado de naturaleza ético (RGV, VI: 93, [117]). Y la forma en la que los seres humanos podemos contribuir a la salida de dicho estado es mediante la erección de una comunidad ética o Estado ético, es decir, mediante la conformación de una unidad bajo leyes públicas de virtud (RGV, VI: 94, [118]). Pero este deber difiere de todos los deberes, por su índole y por su principio, se trata pues de un deber sui generis (RGV, VI: 98, [123]).

La diferencia de este deber sui generis radica, en principio, en que no puede ser cumplido individualmente, sino que se trata de una tarea y de un deber para todo el género humano (RGV, VI: 94, [118]). No se trata de "un deber de los hombres para con los hombres, sino de un deber del género humano para consigo mismo" (RGV, VI: 97, [122]). La especie humana en su conjunto está determinada al deber de la razón pura práctica de alcanzar el bien supremo como un bien comunitario. Esto significa que el fin comunitario no puede ser alcanzado por el esfuerzo del individuo que busca solo su reforma interna, su propia perfección moral (RGV, VI: 97, [122]). Por más que el individuo realice un cambio de corazón y se aplique a la observancia de la ley moral, no alcanza para contrarrestar al principio malo (RGV, VI: 94, [118], sino que este solo se supera con la unión de las personas en orden al mismo fin, a saber, la erección de una comunidad ética para alcanzar el bien supremo. El cumplimiento de dicho deber es comunitario y no individualista.

\footnotetext{
21 Acuerdo con Palmquist en que tanto el deber de salir del estado de naturaleza jurídico como el deber de salir del estado de naturaleza ético son análogos en cuanto que son ambos deberes de la razón pura práctica ( $c f$. Palmquist, S., Comprehensive Commentary on Kant's Religion within the Bounds of Bare Reason, p. 255). Pero ello sin dejar de notar las diferencias en la naturaleza de ambos deberes éticos y jurídicos.
} 
Pero hay una diferencia más que hace a este deber peculiar, a saber, que si bien debemos actuar en orden a una unidad ética, "no podemos saber si está como tal también en nuestro poder" (RGV, VI: 98, [123]). Y esto porque "subjetivamente no pudiese jamás esperarse de la buena voluntad de los seres humanos que ellos se decidiesen a trabajar en concordia en orden a ese fin" (RGV, VI: 95, [119]). Dicha conclusión puede llevar a algunos estudiosos a malinterpretar a Kant y considerar que con ello toma una postura utópica acerca de la comunidad ética ${ }^{22}$. Sin embargo, la postura de Kant refiere a todo lo contrario, pues la idea de una comunidad ética "tiene en la Razón humana su realidad objetiva perfectamente fundada" (RGV, VI: 95, [119]). La idea de una comunidad ética tiene "una realidad práctica objetiva" en el sentido de ser un modelo normativo que sirve para orientar y guiar nuestras prácticas en este mundo terrenal, con vistas a alcanzar el fin último del bien supremo comunitario, aun cuando no sepamos si está en nuestro poder lograrlo. Por otra parte, tampoco Kant es un pesimista, pues si bien no sabemos si está en nuestro alcance la realización de la comunidad ética, sin embargo, debemos actuar como si estuviera en nuestro poder hacerlo, porque si debemos tenemos que poder hacerlo (RGV, VI: 45, [66]).

Por último, además de estas diferencias que Kant menciona explícitamente, podemos agregar una tercera característica que hace a este deber al menos diferente con el exeundum jurídico. Esta característica radica en que es un deber que no puede ser coaccionado, sino que debe ser adoptado libremente. En un pasaje célebre de Religión Kant dice: "En una comunidad política ya existente todos los ciudadanos politicos como tales se encuentran en el estado de naturaleza ético y están autorizados a permanecer en él; pues sería una contradicción (in adjecto) que la comunidad política debiese forzar a sus ciudadanos a entrar en una comunidad ética, dado que esta última ya en su concepto lleva consigo la libertad respecto a toda coacción" (RGV, VI: 95, [120]).

Esto se debe a que las leyes jurídicas obligan solo a nuestras libertades externas con el cumplimiento de la legalidad de nuestras acciones y no a la 326 moralidad de ellas (RGV, VI: 99, [124]). Es decir, no obliga a nuestras libertades

\footnotetext{
${ }^{22}$ Un ejemplo de esta forma de interpretar a Kant la encontramos en Julio De Zan, pues sostiene que la idea de comunidad ética es una utopía porque no designa nada empírico existente en su lugar y equipara, a su vez, la idea de utopía con la del ideal regulativo ( $c f$. De Zan, J., "La utopía kantiana de la comunidad ética", en: Isegoría, 33 (2005), pp. 151ss.). Aquí sostengo lo contrario, pues el hecho de que Kant establezca ideas que sirven como modelo para guiar nuestras prácticas muestra que Kant piensa en ideas relacionadas con las acciones que se dan en este mundo empírico, por tanto, Kant no es utópico, sino que su teoría está mediada por lo práctico.
} 
internas. Así, Kant mantiene una clara distinción entre los dos tipos de legislación, la ética, por un lado, cuyos deberes son no coactivos y son deberes para la libertad interna, y la legislación jurídica, por otro lado, cuyos deberes son coactivos y son deberes solo para la libertad externa. De esta distinción, Kant deriva que estamos autorizados a permanecer en el estado de naturaleza ético porque el poder coactivo del Estado no puede forzarnos a abandonarlo, sino que tiene que ser una elección completamente libre por parte de cada ciudadano "si quiere además entrar en una unión ética con otros conciudadanos o si prefiere permanecer en un estado de naturaleza de esta índole" (RGV, VI: 96, [120]). En otras palabras, el Estado político no puede coaccionar a las personas a ser virtuosas y perseguir fines comunes porque dicho Estado no puede intervenir en los fines que los individuos se propongan, sino que debe dejar a cada uno decidir sus fines y los medios para alcanzarlos ${ }^{23}$ (MS, VI: 381, [230]).

Podemos decir que, por un lado, hay un deber no coactivo de entrar en un estado civil ético y, por otro lado, hay una necesidad de que este deber sea cumplido si queremos dar una solución al conflicto social ético dado por la falta de leyes éticas comunes. Aún con las diferencias, podemos hablar de una analogía entre ambos exeundum, el ético y el jurídico, en cuanto que corresponden a un deber de la razón práctica, aunque se trata de deberes diferentes entre sí.

\section{Las comunidades kantianas}

Queda ahora el tercer momento del paralelismo ético-jurídico que corresponde a la formación de las comunidades ética y política. En lo que sigue sostendré que tanto la unidad ética como la jurídico-política se tratan de una unidad civil, es decir, bajo leyes públicas, pero en cada caso se requiere un principio de unidad diferente.

Kant nos dice que, así como la comunidad política requiere una unidad mediante leyes públicas jurídicas, la comunidad ética también necesita una unidad mediante leyes públicas éticas. Kant define al Estado político (civitas) como "la unión de un conjunto de seres humanos bajo leyes jurídicas" (MS,

\footnotetext{
23 En Metafísica de las Costumbres Kant deja asentado que la ética y el derecho se distinguen por los fines y los deberes: "Fin y deber marcan la distinción entre las dos secciones de la doctrina general de las costumbres. El hecho de que la ética contenga deberes, a cuyo cumplimiento no podemos ser obligados (físicamente) por otros, es simplemente la consecuencia de que sea una doctrina de los fines, porque una coacción dirigida a tenerlos o a proponérselos se contradice a sí misma" (MS, VI: 381, [231]).
} 
§45, VI: 313, [142], traducción enmendada; $R G V$, VI: 95, [118]), mientras que define al Estado ético como aquel en el cual "los seres humanos están unidos bajo leyes no coactivas, esto es: bajo meras leyes de virtud" (RGV, VI: 95, [118]).

Cabe aclarar que, tanto en el dominio jurídico-político como en el ético, Kant establece que los estados de naturaleza correspondientes no se oponen al estado social, sino al estado civil (RGV, VI: 94, [118-119]; MS, VI: 306, [136]) ${ }^{24}$. El espacio público requiere no un mero estado social, sino que tanto la conformación de la comunidad política como la comunidad ética requieren la unidad bajo leyes públicas comunes.

Del lado jurídico, Kant señala, en un pasaje clave de Metafísica de las Costumbres, que debemos abandonar el estado de naturaleza por el siguiente motivo: "Antes de que se establezca un estado legal público, los individuos, pueblos y Estados aislados nunca pueden estar seguros unos de otros frente a la violencia y hacer cada uno lo que le parece justo y bueno por su propio derecho sin depender para ello de la opinión del otro" (MS, VI: 312, [141]).

La única forma de que haya verdaderamente derecho es en un estado civil, para cuya realización es condición de posibilidad (conditio sine qua non) la voluntad de todos unificada a priori, dado que "por medio de una voluntad unilateral no puede imponerse a otros una obligación, que de otro modo no tendrian por si” (MS, VI: 264, [80-81]). Solo bajo la idea de una voluntad universalmente legisladora podemos tener leyes que nos obliguen de manera omnilateral, dado que son leyes que co-legislamos entre todos y a las cuales estamos sometidos todos (MS, VI: 314, [143]). Solo en el estado civil jurídico podemos tener un derecho perentorio (MS, VI: 264, [81]), antes del estado civil solo hay derecho privado. Esto significa que una adquisición de algo exterior "es solo provisional mientras no cuente con la sanción de una ley pública, porque no está determinada por una justicia (distributiva) pública ni asegurada por ningún poder que ejerza ese derecho" (MS, VI: 312, [141]). En cambio, un estado civil es aquel "en el que a cada uno se le determine legalmente y se le atribuya

\footnotetext{
${ }^{24}$ Repongo dos pasajes centrales con los cuales Kant establece que un espacio público refiere tanto a lo jurídico como a lo ético mediante la conformación de los estados civiles correspondientes, los cuales se oponen entre sí: "A una liga de los seres humanos bajo meras leyes de virtud según prescripción de esta idea se la puede llamar sociedad ética y, en cuanto estas leyes son públicas, sociedad civil ética (en oposición a la sociedad civil de derecho) o comunidad ética" (RGV, VI: 94, [118-119], traducción enmendada). "El estado no-jurídico, es decir, aquel en el que no hay justicia distributiva, es el estado natural (status naturalis). A él no se opone el estado social, sino el estado civil (status civilis) de una sociedad sometida a la justicia distributiva" (MS, VI: 306, [136]).
} 
desde un poder suficiente (que no sea el suyo, sino uno exterior) lo que debe ser reconocido como suyo" (MS, VI: 312, [141]).

Del lado ético, Kant dice que dado que debemos avanzar en la erección de una comunidad ética y que no sabemos si está en nuestro poder llevarla a cabo, debido a que no se puede esperar de las voluntades humanas un acuerdo sobre los principios de virtud en disputa, tiene que intervenir la idea de Dios como el principio de unidad que los seres humanos por sí mismos no pueden llevar a cabo. Kant lo dice así: "Se sospechará ya de antemano que este deber necesitará del supuesto de otra idea, a saber: la de un ser moral superior mediante cuya universal organización las fuerzas, por si insuficientes, de los particulares son unidas en orden a un efecto comunal” (RGV, VI: 98, [123]).

La idea de Dios tiene la función de lograr la unidad ética en tanto que Dios es el legislador moral supremo de las leyes públicas de virtud. La religión en Kant posibilita el espacio público que se requiere para dar una solución social al problema ético persistente en las sociedades políticas existentes, las cuales se hallan en estado de naturaleza ético ${ }^{25} 26$. En Religión Kant otorga a Dios el papel de fundador de la comunidad ética, en tanto es el legislador moral supremo de las leyes públicas de virtud, mientras que los seres humanos tienen el rol de ser los autores de la organización de la comunidad ética bajo esas leyes (RGV, VI: 152, [184]).

Pero antes de afirmar a Dios como el legislador comunitario que posibilita la unidad en la conformación de la comunidad ética, Kant descarta dos posibilidades como fuentes de legislación pública ética. Primero, considera a la voluntad unida de todos. Aquí Kant demarca el principio de unidad ético del jurídico-político de forma concluyente. Nos dice que si se trata de una comunidad jurídico-civil, la multitud se une en un todo legislador, en la voluntad general, de la que emana una coacción legal externa (RGV, VI: 98, [123]). Es decir, que en el caso de la comunidad jurídico-civil es la voluntad general el

\footnotetext{
${ }^{25}$ Me refiero a la relación entre la comunidad ética y la comunidad política en la última sección.

${ }^{26}$ Con esta lectura de la religión me alineo con James DiCenso y Pablo Muchnik. Para DiCenso "la comunidad ética sirve como referencia crítica para evaluar y modificar las sociedades politicas existentes en la que nos encontramos. Las leyes de la virtud extienden la justicia no solo más allá del sistema social y legal existente, sino también más allá de los límites de las comunidades parroquiales cerradas, incluidas las religiosas" (DiCenso, J., Kant's Religion within the Boundaries of Mere Reason: A Commentary, p. 137). Muchnik por su parte considera que "la tarea de la religión de Kant está determinada por la incapacidad de la política para moralizar a los seres humanos o, para decirlo de manera positiva, la religión kantiana está diseñada para explicar cómo los demonios podrían deshacerse de su egoísmo y convertirse en buenas personas" (Muchnik, P., "Kant's religious constructivism”, p. 205).
} 
principio de unidad que posibilita un estado de derecho en el que se restringe la libertad de cada uno a las condiciones bajo las cuales pueden coexistir las libertades externas según una ley general ( $R G V$, 98, [123]; MS, VI: 230, [39]). Sin embargo, dice Kant, si pensamos en la conformación de una comunidad ética, el principio de unidad no puede ser la voluntad del pueblo, dado que su legislación corresponde solo a las leyes para nuestras libertades externas y exigen solo la legalidad de las acciones (RGV, VI: 99, [124]). La legislación ética requiere, en cambio, la moralidad de las acciones, es decir, deben estar dirigidas al interior de las acciones. Pero ello no significa que deban estar en un ámbito privado, sino que es necesario una legislación pública para la conformación de un Estado ético.

Ahora bien, así como se descarta la voluntad del pueblo como legislador público ético, también se descarta a la idea de Dios como fuente externa de legislación. Si así fuere, esas leyes serían estatutos y por tanto deberes externos coactivos, lo cual es contradictorio con el hecho de que la virtud no puede ser coaccionada ( $R G V$, VI: 99, [124]). No se trataría de un soberano moral legítimo, sino de una teocracia, en la cual, mediante leyes estatutarias heterónomas, los sacerdotes impondrian órdenes en nombre de un Dios, pero que no serían más que mandatos externos que no se identifican con los mandatos de virtud internos y no coactivos ${ }^{27}$. En una teocracia Dios sería el legislador en tanto que "ciertos hombres en calidad de sacerdotes, que reciben las órdenes directamente de Dios, conducirian un gobierno aristocrático" (RGV, VI: 100, [125]).

La conclusión a la que llega Kant es que solo podemos compatibilizar la moralidad con una legislación pública, si consideramos a Dios como fuente de legislación puramente interna, es decir, como el legislador de las leyes de virtud públicas y a nosotros como un pueblo de Dios bajo esas mismas leyes. A diferencia de los seres humanos, que no podemos penetrar en las intenciones de los otros y que incluso muchas veces tenemos una opacidad de nuestra visión sobre nosotros mismos, Dios es el único que puede conocer los corazones y penetrar en nuestras intenciones y "proporcionar a cada uno aquello que sus

27 En este punto Kant claramente se separa de Hobbes para quien el Leviatán reúne el poder político y eclesiástico. Para Kant la falta de distinción entre la libertad externa y la interna, y por ende la falta de distinción entre las fuentes de legislación interna y externa y sus deberes correspondientes, conlleva a un despotismo teocrático (cf. RGV, VI: 96 [120], 99, [125], 131, [162]; MS, VI: 368, [213]). Para evitar esto, Kant establece la distinción de la comunidad ética y la comunidad política sobre la distinción entre la legislación interna y externa, por un lado, y sus deberes no coactivos y coactivos correspondientes, por el otro (cf. RGV, VI: 98-99, [123-124]; MS, VI: 219-220, [24-25]). De esta forma se evita tanto un poder politico que intervenga en deberes y fines internos, como también la idea de un legislador moral despótico y arbitrario (cf. TP, VIII: 290-291, [41-42]). 
actos merecen" (RGV, VI: 99, [125]). Así es que debemos considerar a nuestros deberes éticos como si fueran mandatos divinos que guian nuestras acciones para alcanzar el fin común del bien supremo en la Tierra. Como bien se ha señalado en la literatura ${ }^{28}$, la ley divina se identifica con la ley moral, la legislación divina no es distinta a nuestra razón práctica, y por ello, es compatible con nuestra autonomía. Lo que aporta la legislación divina es dar un estado público a la ley moral, a la cual todos podemos acceder en tanto agentes morales racionales, porque son mandatos que cada individuo puede encontrar en su propia razón ( $R G V$, VI: 104, [130]).

Así es la manera en que Kant argumenta que para instituir la comunidad ética necesitamos la idea Dios como legislador público interior, dado que las solas fuerzas humanas no alcanzan para tal propósito. Sin embargo, Kant es claro en que ello no significa que los seres humanos debamos permanecer inactivos y esperar que Dios haga todo el trabajo, sino que debemos proceder "como si todo dependiese de él, y solo bajo esta condición se puede esperar que una sabiduria superior concederá a sus bienintencionados esfuerzos su consumación" (RGV, VI: 100-101, [126], traducción enmendada). Si bien la posición de Kant no es del todo secularizada, no deja de darle una función también primordial a los seres humanos, pues la comunidad ética debe ser una organización humana colectiva en un ámbito público, si se quiere salir del estado en el que estos se encuentran por su propia culpa (RGV, VI: 93-94, [117118]). Se trata de una tarea humana cuyo objetivo es alcanzar el mayor grado de virtud y vencer a los males que corresponden a nuestras relaciones éticas.

La manera en que los seres humanos pueden realizar la idea de la comunidad ética en la Tierra, bajo condiciones sensibles, es a través de una institución, a saber, una iglesia. En este sentido Kant dice que "una comunidad ética bajo la legislación moral divina es una iglesia" (RGV, VI: 101, [126]). Asimismo, Kant distingue entre la iglesia invisible y la visible. La iglesia invisible es "una mera idea de la unión de todos los hombres rectos bajo el gobierno divino inmediato, pero moral, del mundo" (RGV, VI: 101, [126], el resaltado es mío). Esta idea elevada, nunca plenamente alcanzable, es el ideal regulativo, que sirve de arquetipo a todas las iglesias visibles que pueden ser fundadas por los seres humanos bajo condiciones sensibles. La iglesia visible es la iglesia en el fenómeno, "es la efectiva unión de los seres humanos en un todo que concuerda

${ }^{28}$ Cf. Wood, A., Kant's Ethical thought, p. 317 y n. 42; DiCenso, J., Kant's Religion within the Boundaries of Mere Reason: A Commentary, p. 143; Muchnik, P., "Kant's religious constructivism”, p. 210. 
con aquel ideal" (RGV, VI: 101, [126], traducción enmendada). La iglesia visible puede, a lo sumo, representar solo la forma de la iglesia invisible, en tanto los seres humanos manifiestan su unidad bajo leyes públicas de virtud.

Como ha señalado James DiCenso, la idea de una comunidad ética "proporciona criterios para evaluar y modificar las instituciones existentes en relación con la ley moral"29. Es decir, que el ideal de la comunidad ética es un modelo a seguir para cambiar a las sociedades éticas parciales existentes, con el fin de acercarnos a la universalidad que implica una comunidad ética. Este ideal de un todo ético reúne todas las sociedades éticas existentes, que sin esa unidad solo son sociedades parciales en estado de naturaleza ético ( $R G V$, VI: 96, [121]).

Pero esta universalidad no debe confundirse con la universalidad jurídicopolítica que implicaría un público derecho de gentes ${ }^{30}$ (RGV, VI: 96, [121]), dado que esta última se refiere a los acuerdos externos jurídicos para alcanzar una condición jurídica que mantenga y proteja la constitución de cada Estado y sus pueblos ${ }^{31}$, mientras que la comunidad ética o República ética universal reflejaría una unidad interna de virtud. En un todo ético estarían coordinados todos nuestros fines y nosotros como fines en sí mismos bajo el fin común del bien supremo comunitario, pero ya no en un nivel de análisis abstracto de los seres racionales, como en Fundamentación de la Metafisica de las Costumbres. Allí Kant define el reino de los fines como "el enlace sistemático de todos los seres racionales por leyes comunes" y como "un todo de todos los fines (tanto de los seres racionales como fines en sí, como también de los propios fines que cada cual pueda proponerse)" (GMS, IV: 433, [52]). En Religión, en cambio, piensa que esta coordinación de fines se daría en un nivel de análisis concreto, pensado desde la vida natural fenoménica de los seres humanos en comunidad, es decir, con sus inclinaciones, sus deseos y con los otros con los que vive. Por ello, Kant habla de la realización del reino de Dios en la Tierra (RGV, VI: 95, [119]). Por otra parte, en Religión Kant habla de comunidades, palabra que reserva para definir la unidad de los seres humanos bajo leyes públicas, ya sean éticas o jurídicas (RGV, VI: 95, [119]).

\footnotetext{
${ }^{29}$ Véase: DiCenso, J., Kant's Religion within the Boundaries of Mere Reason: A Commentary, p. 139; DiCenso, J., "Kant on ethical institutions", p. 51.

${ }^{30} \mathrm{Me}$ dedico a estudiar propiamente la posibilidad del desarrollo moral en y desde el plano del derecho internacional y cosmopolita en: Quiroga, N., "Derecho Internacional y Comunidad ética en Religión de Kant", en: Ágora. Papeles de Filosofia, [en prensa].

${ }^{31} C f$. RGV, VI: 34n, [53]; $Z e F$, VIII: 356, [257]; MS, VI: 350, [191].
} 


\section{Conclusiones sobre el paralelo ético-jurídico}

Para concluir, podemos decir que más allá de las diferencias y semejanzas entre los contenidos de los constructos éticos y jurídico-políticos, Kant establece una analogía basada en la relación estructural entre el estado de naturaleza y el estado civil éticos, por un lado, y el estado de naturaleza y el estado civil jurídico-políticos, por el otro. Así, es claro que de la misma manera que debemos abandonar el estado de naturaleza jurídico y entrar en una condición jurídica-política, de la misma manera debemos abandonar el estado de naturaleza ético y entrar en una comunidad ética ( $R G V$, VI: 97, [122]). Lo que esta analogía señala es que en ambos casos debemos abandonar el estado en el que no hay ley común y en el que cada uno es juez de su propia causa, donde los individuos monopolizan la interpretación y ejecución de la ley y donde las conflictividades, por ello, están siempre latentes cuando no son un hecho. Los individuos que se hallan en dicho estado tienen el deber de pasar a formar una unidad civil bajo leyes públicas comunes a todos.

Esta analogía tiene una función relevante en el texto de Religión, a saber, mostrar la relación que hay entre los dos dominios y cómo cada uno contribuye al progreso en la vida moral de los seres humanos.

Si bien el dominio ético y el jurídico-político se diferencian por tener su principio de constitución y su legislación propios, sin embargo, son dos dominios que están relacionados. En principio su relación está dada en cuanto que comparten el mismo espacio público, desde el cual cada dominio aborda problemas diferentes, el ético los referidos a las libertades internas y el jurídico los referidos a las libertades externas.

La pregunta que guía esta interrelación entre lo ético y lo jurídico-político puede formularse como sigue: ¿Por qué la comunidad política es condición de posibilidad de la comunidad ética? Ello se basa en el siguiente pasaje clave: "[La comunidad ética] puede existir en medio de una comunidad política e incluso estar formada por todos los miembros de ella (de hecho, no podría en absoluto ser llevada a cabo por los seres humanos sin que esta última estuviese a la base)" (RGV, VI: 94, [119], traducción propia).

La respuesta a dicha pregunta es que los individuos en una comunidad política permanecen en estado de naturaleza ético. Pese a tener una unidad bajo leyes jurídicas, estas no atañen a las libertades internas, sino solo a las externas. Las sociedades politicas existentes no son más que sociedades parciales, es decir, solo una representación o esquema del ideal de la comunidad 
ética (RGV, VI: 96, [121]). El estado de naturaleza ético en el que se encuentran las comunidades políticas existentes es aquel en el que los principios de virtud siguen siendo acechados por el mal. El único mal que puede ser abordado por una condición jurídica es el de la falta de leyes comunes jurídicas y el consecuente estado de guerra en cuanto a las relaciones exteriores entre los individuos o Estados.

La conformación de una comunidad ética es necesaria alli donde la coacción del Estado político no llega, a saber, a la virtud de los individuos y a la posibilidad de establecer un fin común comunitario que permita alcanzar el bien supremo comunitario. Kant expresa esta relación entre la comunidad ética y la comunidad política en los siguientes términos: "Quienes se encuentran en una comunidad política pueden desear que en ella se encuentre también un dominio sobre los ánimos según leyes de virtud; pues allí donde sus medios de coacción no alcanzan- porque el juez humano no puede penetrar con la mirada el interior de otros seres humanos- allí podrían las intenciones de virtud efectuar lo requerido" (RGV, VI: 95, [120], traducción enmendada).

La comunidad ética abarca el espacio público al que no llega la comunidad política, pero por tratarse la comunidad política de la base desde donde puede existir una comunidad ética, se encuentran relacionadas en la interacción práctica de los seres humanos. Las restricciones que pone la comunidad ética es que en ella se ingrese libremente y que "en ella no haya nada que este en conflicto con el deber de sus miembros como ciudadanos del Estado" (RGV, VI: 96, [121]). Mientras que el límite del dominio jurídico está en no intervenir en los fines que cada uno se proponga. Solo la comunidad ética puede guiarnos en el fin común del bien supremo y en cómo debemos contribuir cada uno a ese fin común.

En suma, la función de la analogía política, tal como se desarrolla en Religión, es establecer que el espacio público está conformado tanto por el dominio jurídico-político como por el dominio ético. La erección de la comunidad ética es lo que nos permitiría superar el mal radical que se manifiesta en contextos socio-políticos. Para lograr ello debemos, como sostienen Moran y DiCenso ${ }^{32}$, perseguir y promover las instituciones éticas (como ser la educación

\footnotetext{
${ }^{32}$ Como bien han notado Kate Moran y James DiCenso, las instituciones éticas son fundamentales para modificar las sociedades politicas. Por su parte Moran sostiene que las instituciones éticas (como la educación moral y la amistad) hacen que el progreso hacia esta meta de erigir una comunidad ética sea más probable (Moran, K., Community and Progress in Kant's Moral Philosophy, Washington D.C.: Catholic University Press of America, 2012, p. 101). Asimismo, DiCenso sostiene que a través de las instituciones éticas públicas se puede articular y difundir los princi-
} 
moral), las cuales tienen la función de ayudar a orientar nuestras elecciones hacia la ley moral y desviarnos de priorizar el amor propio que propicia el mal social. En este sentido podemos hablar de una ética política kantiana.

Recibido: 09/09/2020

Aceptado: 12/07/2021

\section{Bibliografia}

Anderson-Gold, S., "God and community: An Inquiry into the Religious implications of the Highest Good", en: Rossi, P. y M. Wreen (eds.), Kant's Philosophy of Religion Reconsidered, Bloomington/Indianapolis: Indiana University Press, 1991, pp. 113-131.

Byrd, S. y J. Hruschka, Kant's Doctrine of Right. A Commentary, Cambridge: Cambridge University Press, 2010. https://doi.org/10.1017/CBO9780511712050

De Zan, J., "La utopía kantiana de la comunidad ética”, en: Isegoría, 33 (2005), pp. 143159. https://doi.org/10.3989/isegoria.2005.i33.422

DiCenso, J., Kant's Religion within the Boundaries of Mere Reason: A Commentary, Cambridge: Cambridge University Press, 2012.

DiCenso, J., "Kant on ethical institutions", en: The Southern Journal of Philosophy, v. LVII, 1 (2019), pp. 30-55. https://doi.org/10.1111/sjp.12314

Ebel-Duggan, K., "Moral Community: Escaping the Ethical State of Nature", en: Philosophers' Imprint, v. IX, 8 (2009), pp. 1-19.

Guyer, P., "Kantian Communities: The Realm of Ends, the Ethical Community, and the Highest Good", en: Payne, C. y L. Thorpe (eds.), Kant and the Concept of Community, Nueva York: University of Rochester Press, 2011, pp. 88-120.

Kant, I., (GMS) Grundlegung zur Metaphysik der Sitten, en: Gesammelte Schriften, v. IV, pp. 385-463 [Traducción de Larroyo, F., México D.F.: Porrúa, 2007].

Kant, I., (MS) Die Metaphysik der Sitten, en Gesammelte Schriften, pp. 205-493; (RL) Erster Teil. Metaphysische Anfangsgründe der Rechtslehre, pp. 205-378; (TL) Zweiter Teil. Metaphysische Anfangsgründe der Tugendlehre, pp. 379-491, en: Gesammelte Schriften, v. VI [Traducción de Cortina Orts, A. y J. Conill Sancho, Barcelona: Altaya, 1996].

Kant, I., (RGV) Die Religion innerhalb der Grenzen der bloßen Vernunft, en: Gesammelte Schriften, v. VI, pp. 1-102 [Traducción, prólogo y notas de Martínez Marzoa, F., Madrid: Alianza Editorial, 2007]. 
Kant, I., (TP) Über den Gemeinspruch: Das mag in der Theorie richtig sein, taugt aber nichts für die Praxis, en: Gesammelte Schriften, v. VIII, pp. 273-314 [Traducción de Correa, C., Buenos Aires: Leviatán, 1984].

Kant, I., (ZeF) Zum ewigen Frieden, en: Gesammelte Schriften, v. VIII, pp. 341-386. [Traducción de Larroyo, F., México D.F.: Porrúa, 2007].

Marey, M., "The Originality of Kant's Social Contract Theory", en: Krasnoff, L. y otros (eds.), Kant's Doctrine of Right in the Twenty-first Century, Cardiff: University of Wales Press, 2018, pp. 9-28.

Moran, K., Community and Progress in Kant's Moral Philosophy, Washington D.C.: Catholic University Press of America, 2012.

Muchnik, P., "Kant's religious constructivism”, en: Michalson, G. (ed.), Kant's Religion within the Boundaries of Mere Reason. A critical Guide, Cambridge: Cambridge University Press, 2014, pp. 193-213. https://doi.org/10.1017/ CBO9781139088138.011

Palmquist, S., Comprehensive Commentary on Kant's Religion within the Bounds of Bare Reason, Chichester: Wiley Blackwell, 2016. https://doi. org/10.1002/9781118619599

Papish, L., Kant on evil, Self-Deception, and Moral Reform, Nueva York: Oxford University Press, 2018. https://doi.org/10.1093/oso/9780190692100.001.0001

Pinheiro Walla, A., "Human Nature and the Right to Coerce in Kant's Doctrine of Right”, en: Archiv für Geschichte der Philosophie, v. XCVI, 1 (2014), pp. 126-139. https://doi.org/10.1515/agph-2014-0006

Quiroga, N., "El origen, objetivo y función de la comunidad ética en La religión dentro de los límites de la mera razón de Kant", Anales del Seminario de Historia de la Filosofia, v. XXXVII, 3 (2020), pp. 437-447. https://revistas.ucm.es/index.php/ ASHF / article/view/68320

Quiroga, N., "Derecho Internacional y Comunidad ética en Religión de Kant”, en: Ágora. Papeles de Filosofia, [en prensa].

Rossi, P., The social Authority of Reason: Kant's Critique, Radical Evil, and the Destiny of Humankind, Albany: State University of New York Press, 2005.

Tampio, N., "Pluralism in the Ethical community", en: Gordon M. (ed.), Kant's Religion within the Boundaries of Mere Reason: A critical Guide, Cambridge: Cambridge University Press, 2010, pp. 175-192. https://doi.org/10.1017/ CBO9781139088138.010

Wood, A., Kant's Ethical thought, Cambridge: Cambridge University Press, 1999. 